\title{
Análisis inicial de la Segunda Temporada de Pesca de Anchoveta 2017
}

Elaborado por la Dirección Científica de Oceana en Perú

\section{OCEANA ${ }^{\text {Protegiendo los }}$ Océanos del Mundo}

Lima, 24 de noviembre de 2017 


\section{Análisis inicial de la Segunda Temporada de Pesca de Anchoveta 2017 y los retos que representa}

Lima, noviembre de 2017. El pasado viernes 17 se anunció el inicio de la segunda temporada de pesca del stock-norte centro de anchoveta estableciéndose una cuota total de pesca de 1.49 millones de toneladas sobre un estimado de biomasa de 6.06 millones de toneladas. La documentación técnica* que sustenta los cálculos de dicha cuota y los resultados de evaluaciones previas realizadas en agosto y setiembre últimos, recién fueron publicados el lunes 20 a pesar de múltiples solicitudes previas para acceder a dicha información.

\section{*Descarga los informes aquí: https://goo.gl/3ZouV2}

En la evaluación rápida de la documentación disponible destaca la elevada proporción de juveniles presentes en el stock ( $96 \%$ en frecuencia y $67 \%$ en peso). En otras palabras, por cada kilo de anchoveta en el mar, alrededor de 700 gramos son ejemplares con tallas menores a los $12 \mathrm{~cm}$. La última vez que se registraron proporciones tan altas de juveniles fue a finales del 2014 (97\%) lo cual, unido a la baja biomasa encontrada, condujo a la no apertura de la segunda temporada de pesca. Este cierre permitió la recuperación del stock para la primera temporada del año siguiente.

Por el lado positivo, una elevada cantidad de juveniles refleja la capacidad reproductiva del recurso a pesar de las condiciones oceanográficas alteradas a las que ha estado sometido en los últimos años. Sin embargo, se debe reconocer que el stock adulto ha sido estimado en cerca de 2 millones de toneladas, valor muy por debajo de los 4 millones de stock mínimo reproductivo que se esperaba tener luego de la primera temporada de pesca de acuerdo al protocolo empleado para el cálculo de la cuota.

Además, la elevada proporción de juveniles en el stock implica que inexorablemente se producirán elevadas capturas de éstos en las redes de pesca, ya que no existen tecnologías prácticas implementadas para prevenirlo. La principal herramienta de manejo con la que se cuenta en el país es el cierre preventivo de las áreas donde se detecte la presencia de juveniles. Sobre este particular, debe recordarse que con la emisión del DS 024-2016-PRODUCE ya no se sanciona la captura de juveniles sin importar cuan alto sea el porcentaje en tanto se haga el reporte oportuno de la ocurrencia. Aunque esta norma pretende sincerar la información sobre pesca de juveniles y con ello reducir los descartes en alta mar, aún no se ha probado su efectividad y el impacto que la pesca no discriminada de juveniles puede tener en la capacidad de renovación del stock.

Es saludable que IMARPE haya incluido en sus recomendaciones el establecer un tope de $21 \%$ como volumen máximo de juveniles a ser capturados en esta temporada, aunque hubiera sido recomendable que este tope se incluya en la Resolución Ministerial correspondiente tal como se hace con la cuota de pesca. Asimismo, es oportuno recordar que, durante la segunda temporada del año 2016 , con una menor frecuencia de juveniles (86\%), se pescaron cerca del $18.27 \%$ en volumen de acuerdo a PRODUCE. A ello hay que añadir los volúmenes no reportados de enmalles de ejemplares pequeños que representan en la actualidad alrededor del $20 \%$ de la biomasa total y que, de acuerdo a las evidencias de la segunda temporada del 2016, fueron bastante frecuentes. En particular, la apertura de la pesca exploratoria por cuatro días, durante los cuales se trae a puerto todo lo que se captura sin importar su talla, representa un riesgo adicional para la fracción juvenil, y por lo tanto para la capacidad de regeneración del stock. 
De acuerdo a los resultados de la evaluación del stock desovante por el método de producción de huevos realizada en agosto último y a los reportes periódicos de reproducción producidos por IMARPE, la anchoveta se estaría reproduciendo constantemente a lo largo del año como respuesta a las condiciones cambiantes del ecosistema marino. Esto explicaría la presencia de juveniles durante todo el año y el bajo contenido de grasa de las hembras debido al desgaste ocasionado por la producción constante de huevos unido a la baja productividad marina de los últimos años.

Aun cuando la tabla de decisiones sobre la cual se elaboran los escenarios de pesca y su riesgo asociado no ha sido hecha pública, al momento de calcular la cuota de pesca de esta temporada, se ha asumido un riesgo de $50 \%$ de no alcanzar un stock mínimo de cuatro millones de toneladas de stock desovante al inicio de la siguiente temporada reproductiva. Este nivel de riesgo es muy elevado dado que no se cuenta con un stock reproductivo suficientemente alto y que además la pesca de una fracción importante del stock juvenil es inevitable.

\section{Retos}

El sector pesquero también deberá afrontar nuevos retos ya que como señala IMARPE, la persistencia de condiciones frías, aunque positiva para el recurso, conlleva a su dispersión y, por lo tanto, se reduce su disponibilidad para la pesca. Esto significará un mayor esfuerzo de pesca y menores capturas.

En este contexto, la apertura y la cuota de la segunda temporada de pesca representan una apuesta arriesgada con discutibles resultados económicos. Llevarla adelante implica que tanto el sector público como el privado deberán colaborar estrechamente para optimizar los tiempos de reporte y cierre de la pesca en las áreas en las que se detecten concentraciones altas de juveniles. Esto, unido al acceso oportuno a la información y a los reportes oficiales del sector, ayudarían a reducir la incertidumbre y la percepción de falta de transparencia sobre el manejo del recurso.

Hay que considerar que las múltiples evaluaciones realizadas por IMARPE indican claramente que el stock de anchoveta se recupera paulatinamente luego de varios años de condiciones adversas. El escenario a corto plazo sería positivo ante la proximidad de La Niña; sin embargo, la pesca en esta segunda temporada podría limitar seriamente la capacidad de renovación del stock si es que no se refuerzan las medidas de control y vigilancia para reducir la captura de juveniles y no se implementan mecanismos de control ciudadano adecuados.

\section{Participación Ciudadana}

PRODUCE ya cuenta con mecanismos como SOS Pesca (소 y Android) y recepción de denuncias sobre actividades ilegales a través de WhatsApp (955-121-683) y el correo electrónico pescailegal@produce.gob.pe. El esperado sistema de seguimiento satelital TRASAT de la actividad pesquera aún no está operativo, pero herramientas alternativas como Global Fishing Watch permiten el seguimiento de parte de la flota. Es de esperar que la recepción y verificación objetiva de las evidencias reportadas por los pescadores y el público en general ayuden a mejorar el control y supervisión durante esta temporada. 